\title{
INDEK PENGARANG
}

\section{A}

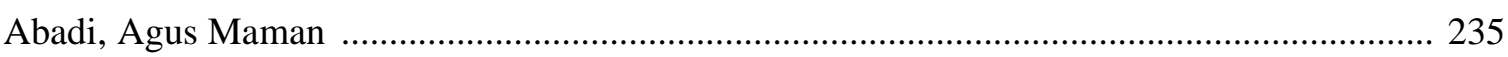

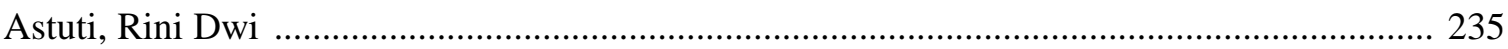

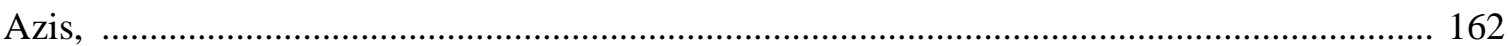

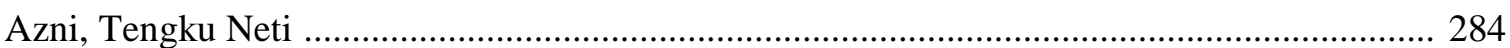

\section{$\mathbf{H}$}

Hartono,

\section{$\mathbf{J}$}

Jailani,

M

Mahmudi, Ali

$175,221,222,274,282$

Marlissa, Inggrid

Marsigit, 224

Melianingsih, Nuning

\section{$\mathbf{P}$}

Putri, Runtyani Irjayanti

$\mathbf{R}$

Retnawati, Heri

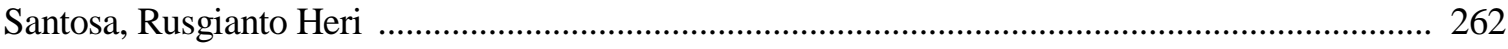

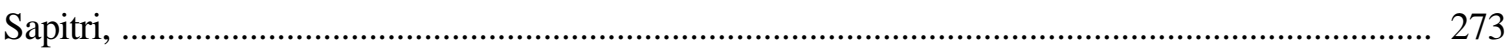

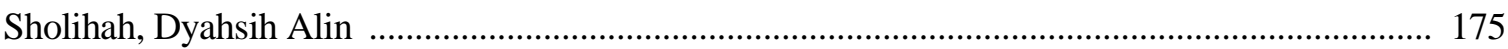

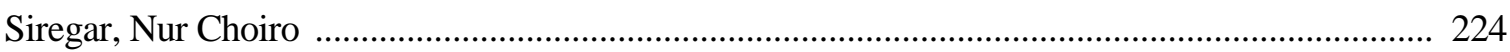

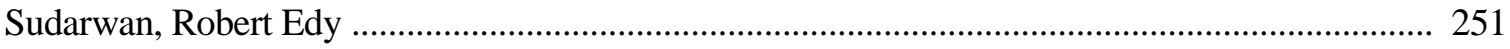

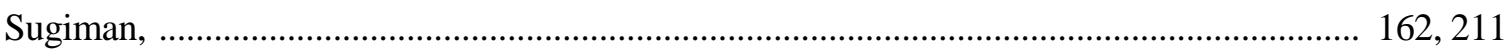

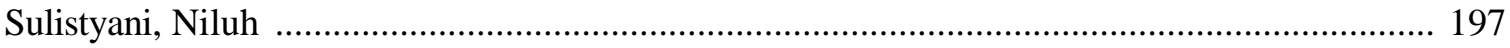

$\mathbf{T}$

Trisnawati, 296

\section{W}

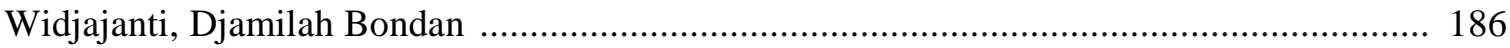

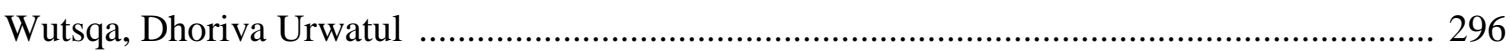




\section{INDEK SUBJEK}

A

afektif, $. .162,164,165,166,167,168,172,177,179,182,184,187,198,226,241,265,299$

apresiasi matematika, 175

apresiasi siswa, $.175,179,180,182,183,184,185,186,189,190,191,192,193,194,195$ aspek analogi, $224,227,230,231,232,233,234$ assessment, $185,197,209,222,249,251,252,253,254,255,256,257,258,259,260,261,272$

B

bangun ruang SMP, 197

berpikir kritis, 180, 182, 196, 197, 198, 199, 200, 201, 202, 203, 204, 206, 207, 208, 209, 234, 237, $273,274,275,276,277,278,279,280,281,282$

D

discovery, $224,226,227,230,231,232,233,234$

$\mathbf{E}$

experiential learning, $175,179,180,181,182,183,184$

G

GI, $273,275,276,277,278,279,280,281,282$

\section{$\mathbf{J}$}

Jigsaw, $235,237,238,239,241,242,243,244,245,246,247,248,250,276$

\section{K}

kecerdasan emosional spiritual, $224,225,227,228,230,231,232,233$

kemampuan penalaran, $219,220,224,232,242,243,244$

kemampuan komunikasi matematis, 211, 212, 215, 220, 221, 273, 274, 276, 277, 278, 279, 280, 281, 282, 284, 286, 290, 291, 293

kemampuan penalaran, 211, 212, 213, 214, 215, 216, 217, 218, 219, 220, 221, 224, 225, 226, 227 , $228,229,230,231,232,233,234,235,237,238,241,242,243,244,245,246,247,248,250,276$, 282

kesulitan belajar matematika, $162,164,165,166,168,169,171,172,173$ kognitif, 1, 164, 165, 169, 172, 173, 174, 177, 179, 182, 183, 186, 187, 188, 189, 190, 192, 193, 195, 196, 198, 226, 234, 241, 265, 266, 275, 288, 293, 299

konvensional, 175, 180, 181, 182, 183, 184, 189, 190, 191, 192, 193, 194, 195, 197, 208, 231, 232, $233,262,266,267,268,269,271$ 


\section{Jurnal Riset Pendidikan Matematika, 2 (2), November 2015}

$\mathbf{M}$

model quantum teaching, $297,300,302,304,305$

model TGT, $296,300,302,303,305$

motivasi belajar, $164,289,296,299,300,301,302,303,304,305,306$

\section{$\mathbf{P}$}

pendekatan open-ended, $211,213,214,215,219,220,221$

pendekatan problem solving, $211,214,215,219,220,221,222$

pengembangan, 178, 197, 199, 201, 202, 203, 204, 205, 206, 209, 213, 225, 251, 253, 255, 256, 257 , $258,259,260,274,284,290,292,294$

perangkat pembelajaran, 197, 199, 201, 203, 205, 206, 207, 208, 268, 276, 284, 285, 290, 291, 292, 293

prestasi belajar, .176, 179, 183, 192, 224, 227, 231, 262, 265, 268, 269, 276, 287, 296, 299, 302, 304 prestasi belajar, 164, 166, 175, 176, 179, 180, 181, 182, 183, 184, 186, 188, 189, 190, 191, 192, 193, 194, 195, 224, 225, 226, 227, 228, 229, 230, 231, 232, 233, 234, 237, 260, 262, 265, 266, 267, 268, $269,270,271,275,276,277,279,287,292,296,298,299,300,301,302,303,304,305$

problem-based learning, $197,200,201,203$

\section{$\mathbf{R}$}

REACT, $186,189,190,191,192,193,194,195,196,262,266,267,268,269,270,271,272$

$\mathbf{S}$

Self efficacy, $262,264,265,266,267,268,269,271,272$ sikap belajar matematika, 235, 236, 237, 238, 241, 242, 243, 244, 245, 246, 247, 248

STAD, 248, 273, 275, 276, 277, 278, 279, 280, 281, 282, 284, 287, 288, 290, 291, 292, 293, 294, 295, 300

strategi inkuiri, 284

\section{$\mathbf{T}$}

TAI, 235, 237, 238, 240, 241, 242, 243, 244, 245, 246, 247, 248, 276 trigonometri, 196, 284, 286, 287, 290, 291, 292, 293

\section{$\mathbf{U}$}

ujian nasional SMA, $162,173,174$

Copyright (C) 2015, Jurnal Riset Pendidikan Matematika Print ISSN: 2356-2684, Online ISSN: 2477-1503 


\title{
BIODATA PENULIS
}

\begin{abstract}
Ali Mahmudi
Ali Mahmudi, lahir pada tanggal 23 Juni1973. Jenjang pendidikan yang telah dilalui yaitu strata satu di Universitas Sebelas Maret lulus pada tahun 1997, strata dua di Universitas Negeri Surabaya lulus pada tahun 2003, serta menempuh pendidikan doktoral di Universitas Indonesia lulus pada tahun 2010. Saat ini aktif sebagai dosen di Jurusan Matematika Fakultas Matematika dan Ilmu Pengetahuan Alam (FMIPA) Universitas Negeri Yogyakarta (UNY) dengan bidang keahlian Pendidikan Matematika.
\end{abstract}

\section{Azis}

Kelahiran 29 September 1987 di Kadolo Katapi, Kota Baubau. Alamat rumah di Jalan Pahlawan Km. 4, Kelurahan Bukit Wolio Indah, Kecamatan Wolio, Kota Baubau, Sulawesi Tenggara. Menyelesaikan Program Sarjana pada Jurusan Pendidikan Matematika Universitas Dayanu Ikhsanuddin Baubau Sulawesi Tenggara pada tahun 2009, Program Magister Jurusan Pendidikan Matematika Program Pascasarjana (PPs) UNY tahun 2014. Alamat e-mail azis_nasam@yahoo.com.

\section{Agus Maman Abadi}

Dilahirkan di Gunungkidul pada tanggal 28 Agustus 1970. Pendidikan S-1 diselesaikan pada tahun 1994 di Prodi Matematika FMIPA, Universitas Gadjah Mada. Pendidikan S-2 diselesaikan pada tahun 1998 di Prodi Matematika FMIPA, Universitas Gadjah Mada. Pendidikan S-3 diselesaikan pada tahun 2011 di Prodi Matematika konsentrasi matematika terapan, FMIPA Universitas Gadjah Mada. Saat ini bekerja sebagai dosen tetap di Jurusan Pendidikan Matematika, FMIPA Universitas Negeri Yogyakarta. Konsentrasi penelitian saat ini adalah sistem fuzzy dan aplikasinya. E-mail: agusmaman@uny.ac.id.

\section{Dhoriva Urwatul Wutsqa}

Dosen Pendidikan Matematika FMIPA UNY dan PPs UNY dengan bidang keahlian Statistika. Dilahirkan pada tanggal 31 Maret 1966. Lulus pendidikan S-1 bidang Matematika/Statistika di Universitas Gadjah Mada (UGM) tahun 1989, Lulus pendidikan S-2 bidang Matematika/Statistika di Institut Teknologi Bandung (ITB) tahun 1993, dan pendidikan program doktor bidang Matematika/ Statistika UGM pada tahun 2008.

\section{Djamilah Bondan Widjajanti}

Dilahirkan pada tanggal 3 Maret 1961. Pendidikan sarjana diselesaikan pada tahun 1985 pada Prodi Matematika Universitas Gadjah Mada. Pendidikan magister pada tahun 1994 di Prodi Matematika ITB, dan program Doktor pada tahun 2010 di Program Studi Pendidikan Matematika Universitas Pendidikan Indonesia Bandung. Saat ini menjadi dosen tetap di Universitas Negeri Yogyakarta.

\section{Dyahsih Alin Sholihah}

Lahir pada tanggal 17 Februari 1989 di Kulon Progo, Daerah Istimewa Yogyakarta. Lulus S-1 Pendidikan Matematika pada tahun 2011 di FMIPA UNY dan S-2 Pendidikan Matematika PPs UNY pada tahun 2014 di Universitas Negeri Yogyakarta.Alamat tempat tinggal di Dusun Sumoroto, Desa Sidoharjo, Kecamatan Samigaluh, Kabupaten Kulon Progo, Provinsi Daerah Istimewa Yogyakarta.

\section{Hartono}

Lektor Kepala Jurusan Pendidikan Matematika FMIPA UNY bidang keahlian Matematika Terapan. Menamatkan pendidikan S-1 di Universitas Gadjah Mada bidang Matematika pada tahun 1981, pendidikan S-2 di Insitut Teknologi Bandung pada tahun 1994, dan pendidikan S-3 bidang Matematika di Delft University of Technology, The Netherlands pada tahun 2004. 


\section{Jurnal Riset Pendidikan Matematika, 2 (2), November 2015}

\section{Heri Retnawati}

Dosen Program Pascasarjana UNY dengan bidang keahlian Asesmen Pendidikan Matematika. Menamatkan Pendidikan Strata-1 pada Program Pendidikan Matematika IKIP Yogyakarta pada tahun 1996, menamatkan S-2 pada Program Penelitian dan Evaluasi Pendidikan pada tahun 2003 di PPs UNY, kemudian melanjutkan Program S-3 pada Program Penelitian dan Evaluasi Pendidikan tahun 2008. Penulis dapat dihubungi via email di retnawati.heriuny1@gmail.com.

\section{Inggrid Marlissa}

Lahir di Ambon pada tanggal 2 Maret 1985. Menyelesaikan pendidikan S-1 di Universitas Pattimura Ambon dan menyelesaikan pendidikan S-2 pada program studi Pendidikan Matematika, PPs Universitas Negeri Yogyakarta. Saat ini bekerja sebagai dosen Universitas Musamus Merauke, Papua. Alamat email yang dapat dihubungi inggridmarlissa@yahoo.com.

\section{Jailani}

Lektor Kepala Prodi Pendidikan Matematika dengan bidang keahlian pendidikan matematika dan Penelitian dan Evaluasi Pendidikan Matematika. Menyelesaikan S-1 Pendidikan Matematika IKIP Surabaya 1984, S-2 Pendidikan Matematika IKIP Malang 1990, dan S-3 Penelitian dan Evaluasi Universitas Negeri Jakarta 2002. Alamat e-mail: zailani_uny@yahoo.com dan jailani@uny.ac.id.

\section{Niluh Sulistyani}

Lahir di Kulon Progo, 14 Juni 1990. Niluh menamatkan Pendidikan Strata-1 pada Program Studi Pendidikan Matematika, Jurusan Pendidikan Matematika, Fakultas Matematika dan Ilmu Pengetahuan Alam Universitas Negeri Yogyakarta pada tahun 2012 dan pendidikan strata-2 di Prodi Pendidikan Matematika PPs UNY tahun 2014. Mulai tanggal 1 September 2014. Penulis bekerja sebagai tenaga pengajar di program studi Pendidikan Matematika FKIP Universitas Sanata Dharma Yogyakarta.

\section{Nuning Melianingsih}

Dilahirkan di Indramayu, 27 Mei 1989. Menyelesaikan studi S-1 di Universitas Negeri Yogyakarta pada tahun 2011 dan S-2 Pendidikan Matematika pada tahun 2014 di PPs Universitas Negeri Yogyakarta. Saat ini mengajar di Madrasah Aliyah Unggulan Al-Imdad Bantul, Yogyakarta.

\section{Nur Choiro Siregar}

Lahir di Palopat Maria, Padang Sidempuan Sumatera Utara pada tanggal 15 November 1989. Menyelesaiakan pendidikan S-1 program studi Pendidikan Matematika di STKIP "TAPSEL" Padang Sidimpuan dan menyelesaiakan S-2 program studi Pendidikan Matematika di PPs Universitas Negeri Yogyakarta.

\section{Marsigit}

Guru Besar Jurusan Pendidikan Matematika FMIPA UNY bidang keahlian pendidikan Matematika. Menyelesaikan pendidikan sarjana di FKIE IKIP Yogyakarta bidang Pendidikan Matematika tahun 1981, pendidikan magister di University of London bidang Pendidikan Matematika tahun 1996, dan pendidikan doktor di Universitas Gadjah Mada bidang Filsafat Matematika pada tahun 2007.

\section{Rini Dwi Astuti}

Lahir di Sleman, 12 Februari 1988. Pendidikan S-1 di Program studi Pendidikan Matematika Universitas Islam Negeri Sunan Kalijaga Yogyakarta diselesaikan tahun 2010. Pendidikan S-2 di Progam Studi Pendidikan Matematika PPs Universitas Negeri Yogyakarta diselesaikan tahun 2013. Pernah menjadi guru matematika di SMA Muhammadiyah 4 Yogyakarta dan saat ini penulis menjadi guru matematika di SMA N 1 Prembun. Alamat email rinidwia.88@gmail.com 


\section{Jurnal Riset Pendidikan Matematika, 2 (2), November 2015}

\section{Robert Edy Sudarwan}

Dilahirkan di Way Kanan Lampung pada tanggal 30 Oktober 1988. Pendidikan S-1 diselesaikan pada tahun 2011 di Prodi Pendidikan Matematika Fakultas Tarbiyah dan Keguruan, UIN Lampung. Pendidikan S-2 diselesaikan pada tahun 2014 di Program Pascasarjana Universitas Yogyakarta. Saat ini sedang menempuh Pendidikan S-3 Penelitian dan Evaluasi Pendidikan di Universitas Negeri Jakarta. Mengajar di Prodi Pendidikan Matematika UM Lampung dan FTK UIN Lampung. Konsetrasi penelitian saat ini adalah evaluasi pendidikan dan pembelajaran pada pendidikan matematika. E-mail: redysudarwan@gmail.com.

\section{Runtyani Irjayanti Putri}

Lahir di Kulonprogo, 2 Februari 1988. Runtyani Irjayanti Putri menamatkan Pendidikan Strata-1 pada Program Studi Pendidikan Matematika, Jurusan Pendidikan Matematika, Fakultas Matematika dan Ilmu Pengetahuan Alam (FMIPA) Universitas Negeri Yogyakarta pada tahun 2011.

\section{Rusgianto Heri Santoso}

Profesor dalam bidang Teknologi Pembelajaran yang dilahirkan pada tanggal 17 April 1949. Pendidikan S-1 pada bidang Pendidikan Ilmu Pasti di IKIP Yogyakarta, pendidikan S-2 bidang Teknologi Pendidikan di IKIP Jakarta, kemudian pendidikan doktor Teknologi Pendidikan di Universitas Negeri Jakarta.

\section{Sapitri}

Dilahirkan di Jambi pada tanggal 29 September 1985. Mendapatkan gelar sarjana dari Prodi Matematika IAIN Sulthan Thaha Saifuddin Jambi pada tahun 2008, dan gelar magister Pendidikan Matematika di PPs UNY pada tahun 2013. Bekerja sebagai tenaga pengajar di Fakultas Tarbiyah IAIN Sulthan Thaha Saifuddin Jambi.

\section{Sugiman}

Kelahiran 28 Februari 1965 di Kutoarjo, Kabupaten Purworejo. Menyelesaikan Program Sarjana pada Jurusan Pendidikan Matematika IKIP Yogyakarta tahun 1989, Program Magister pada Jurusan Matematika ITB tahun 1997, dan Program Doktor pada Program Studi Pendidikan Matematika Pascasarjana UPI tahun 2010. Sejak tahun 1991 hingga sekarang mengajar di Jurusan Pendidikan Matematika Universitas Negeri Yogyakarta. Alamat e-mail sugiman@uny.ac.id.

\section{Tengku Neti Azni}

Lahir di Pekanbaru pada tanggal 23 Agustus 1985. Menyelesaikan pendidikan S-1 jurusan Pendidikan Matematika di Universitas Islam Riau pada tahun 2008. Pada tahun 2012 melanjutkan pendidikan S-2 pada program studi Pendidikan Matematika,PPs Universitas Negeri Yogyakarta. Saat ini bekerja sebagai guru matematika di SMAN Bernas Kabupaten Pelalawan, Riau.

\section{Trisnawati}

Lahir di Magelang pada tanggal 26 November 1988. Lulus S-1 Pendidikan Matematika pada tahun 2011 di FMIPA Universitas Negeri Yogyakarta dan S-2 Pendidikan Matematika pada tahun 2014 di Universitas yang sama. Saat ini bekerja sebagai guru di SMA Muhammadiyah 5 Yogyakarta. Alamat email yang dapat dihubungi trysnasuccesgirl@yahoo.com. 


\section{KETENTUAN PENULISAN ARTIKEL JURNAL RISET PENDIDIKAN MATEMATIKA}

1. Artikel yang dimuat merupakan hasil penelitian dan kajian ilmiah tentang pembelajaran dan Pendidikan Matematika yang belum pernah dipublikasikan.

2. Panjang artikel 10-15 halaman, satu spasi, kertas kwarto A4, margin: kiri dan atas $3 \mathrm{~cm}$, kanan dan bawah $2 \mathrm{~cm}$, font: Times New Roman 11.

3. Artikel dibuat rangkap dua (Hard file dan Soft file dalam CD) dikirim ke Sekretariat Dewan Redaksi Jurnal Riset Pendidikan Matematika Program Studi Pendidikan Matematika, Program Pascasarjana, Universitas Negeri Yogyakarta (UNY), Gedung Baru Program Pascasarjana Lantai 3, Jl. Colombo No. 1, Karangmalang Yogyakarta 55281, Telephone: (0274) 586168 pesawat 229 atau (0274) 550836, Facsimile: (0274) 520326, dan bisa dikirim via Email: jrpm.ppsuny @ gmail.com. atau jrpm.ppsuny@uny.ac.id. Format penulisan artikel mengikuti template yang ada (link atau minta dikirimkan via email).

4. Artikel ditulis menggunakan bahasa Indonesia baku.

5. Judul dalam bahasa Indonesia, ditulis dengan huruf TNR-11 bold, maksimal 16 kata, rata tengah. Untuk judul versi bahasa Inggris ditulis dengan huruf TNR-11 bold, rata tengah. Judul harus jelas, informatif, menarik, visioner, aktual, dan mengandung kata kunci.

6. Nama penulis ditulis tanpa gelar dengan mencantumkan instansi asal dan alamat email.

7. Abstrak ditulis dalam bahasa Indonesia dan, bahasa Inggris terdiri atas 100 hingga 200 kata yang ditulis dalam narasi paragraf, memuat:

a. Hasil Penelitian: Tujuan, metode, dan hasil penelitian.

b. Kajian ilmiah: Permasalahan dan pembahasan.

diketik 1 spasi, disertai dengan kata kunci yang mencerminkan substansi artikel.

8. Isi atau batang tubuh artikel memuat:

a. Hasil Penelitian:

Judul, nama penulis tanpa gelar, instansi asal, alamat email, abstrak, kata kunci, isi meliputi: Pendahuluan: latar belakang, permasalahan, dan landasan teori (dengan ketentuan latar belakang, permasalahan, dan landasan teori tidak ditulis dalam sub-bab tetapi menjadi satu bagian); Metode; Hasil dan Pembahasan; dan Simpulan), Daftar Pustaka, dan biodata penulis.

b. Kajian ilmiah:

Judul, nama penulis tanpa gelar, instansi asal, alamat email, abstrak, kata kunci, isi (Pendahuluan, Pembahasan, dan Simpulan), daftar pustaka, dan biodata penulis.

9. Penunjukan sumber acuan, daftar pustaka dan tabel ditulis dengan format/gaya APA Style:

10. Gambar, grafik, dan tabel disajikan dengan ketentuan:

a. Foto untuk gambar harus cukup tajam, dicetak di atas kertas mengkilap (glossy).

b. Ukuran gambar, grafik, tabel, dan sebagainya disesuaikan dengan ukuran kertas.

c. Gambar dan grafik dibuat di atas kertas putih dan diberi nomor urut dan diacu dalam teks.

d. Judul tabel di tengah atas.

e. Judul gambar, grafik, ditulis di tengah bawah.

11. Biodata penulis ditulis dalam bentuk narasi/paragraf, maksimum 100 kata, memuat nama lengkap dan gelar pendidikan, tempat dan tanggal lahir, pekerjaan, nama lembaga/instansi tempat bekerja, nomor telephone dan alamat email.

12. Beberapa kemungkinan tentang artikel yang dikirimkan: (diterima dan diterbitkan, diterima dengan perbaikan oleh redaksi, diperbaiki untuk dipertimbangkan kembali, ditolak karena tidak memenuhi syarat).

13. Artikel yang tidak diterbitkan akan dikembalikan bila disertai amplop beralamat penulis dan perangko secukupnya.

14. Batasan jumlah artikel yang dimuat adalah $\mathbf{1 2}$ artikel per edisi.

15. Isi artikel sepenuhnya menjadi tanggung jawab penulis.

16. Batas pengiriman artikel maksimal 1 bulan sebelum terbit. 